\title{
A CLINICAL STUDY OF RHEUMATOLOGICAL MANIFESTATIONS IN PATIENTS WITH TYPE 2 DIABETES MELLITUS
}

\author{
Vineetha Kolar Venkataravanappa ${ }^{1}$, Anand Sorikunte Huchappa ${ }^{2}$ \\ ${ }_{1}^{1}$ Assistant Professor, Department of General Medicine, Sree Siddhartha Medical College, Tumkur. \\ ${ }^{2}$ Associate Professor, Department of Radio-Diagnosis, Sree Siddhartha Medical College, Tumkur.
}

\section{ABSTRACT}

\section{OBJECTIVES}

Type 2 diabetes mellitus is associated with various rheumatological manifestations that are debilitating and affect the quality of life. The present study is about prevalence of rheumatological manifestations in type 2 diabetics.

\section{METHODS}

The current study is a cross sectional study with 100 patients of type 2 diabetics and 50 patients of age and sex matched non diabetics were examined for rheumatological manifestations during the period July 2008 to July 2010. The Rheumatological manifestations are documented and prevalence rates were calculated in percent of total cases in each group using Fisher's exact test and Chi-square test.

\section{RESULTS}

Rheumatological manifestations were seen in 31\% patients with type 2 diabetes mellitus compared to $16 \%$ in non-diabetics. Periarthritis of shoulder was seen in 18\% diabetics compared to $4 \%$ in non-diabetics and was statistically significant. Diffuse idiopathic skeletal hyperostosis was observed in 3\% of diabetics. Osteoarthritis of knee was noted in $8 \%$ of diabetics compared to $10 \%$ of non-diabetics. Carpal tunnel syndrome was seen in $3 \%$ of diabetics and $2 \%$ non-diabetics. The manifestations were more predominant in females $43.6 \%$ as compared to males $23 \%$.

\section{CONCLUSION}

Rheumatological manifestations are more prevalent in type 2 diabetics than non-diabetics especially periarthritis of shoulder.

\section{KEYWORDS}

Diabetes, Rheumatological Manifestations, Periarthritis of Shoulder.

HOW TO CITE THIS ARTICLE: Venkataravanappa VK, Huchappa AS. "A clinical study of rheumatological manifestations in patients with type 2 diabetes mellitus.” Journal of Evolution of Medical and Dental Sciences 2015; Vol. 4, Issue 103, December 24;

Page: 16890-16898, DOI: 10.14260/jemds/2015/2541

\section{INTRODUCTION}

Diabetes mellitus is a chronic metabolic condition characterised by persistent hyperglycemia resulting from defects in insulin secretion, insulin action or both. It is associated with long-term damage, dysfunction and failure of various organs, especially the eye, kidneys, nerves, blood vessels and skeletal system.

Although the other complications of diabetes mellitus are recognised as the major causes of morbidity and mortality, the musculoskeletal or rheumatological manifestations associated with it may be very debilitating. Many of these complications are treatable with resultant improvement in quality of life and more independence in activities of daily living. Some of the manifestations like adhesive capsulitis of shoulder and diffuse idiopathic skeletal hyperostosis have a close association with diabetes mellitus that they often lead to diagnosis of diabetes in otherwise asymptomatic patients.

\section{MATERIALS AND METHODS}

One hundred patients with type 2 diabetes mellitus and fifty cases of age and sex matched non diabetics recruited for study at Father Muller Medical College and Hospital.

Financial or Other, Competing Interest: None.

Submission 02-12-2015, Peer Review 03-12-2015,

Acceptance 19-12-2015, Published 24-12-2015.

Corresponding Author:

Dr. Vineetha Kolar Venkataravanappa,

Byraweshwara Krupa, 2 Cross,

$1^{\text {st }}$ Main Jayanagar East,

Tumkur-572102,

Karnataka.

E-mail: drvineetha.anand@gmail.com

DOI: $10.14260 /$ jemds/2015/2541
One hundred patients with type 2 diabetes mellitus, both inpatients and outpatients at Father Muller Medical College Hospital and 50 non-diabetics were included in the study.

\section{Inclusion Criteria}

The criteria for diagnosis of diabetes mellitus laid down by the American Diabetes Association, 2007, with FBS $>126 \mathrm{mg} / \mathrm{dl}$, PPBS $>200 \mathrm{mg} / \mathrm{dl}$ and symptoms of diabetes plus random blood glucose $>200 \mathrm{mg} / \mathrm{dl}$ is followed. The control group included patients without family history of diabetes mellitus, fasting blood sugar values $<126 \mathrm{mg} / \mathrm{dl}$ and postprandial blood sugar values $<200 \mathrm{mg} / \mathrm{dl}$.

\section{Exclusion Criteria}

- Patients with history of injury or fractures, end stage renal disease, chronic liver disease with rheumatoid arthritis.

\section{PROCEDURE}

One hundred patients with type 2 diabetes mellitus, both inpatients and outpatients at Father Muller Medical College Hospital and 50 non-diabetics were included in the study. Demographic characteristics such as age and sex were recorded. Symptoms suggestive of joint involvement such as pain, stiffness, restriction of joint movement and swelling of the joint with the duration of symptoms were documented. General physical examination with vital parameters, anthropometric measurements were recorded. Detailed systemic and musculoskeletal system examination was done and findings are documented and tabulated. Essential investigations were done wherever necessary. 


\section{STATISTICAL ANALYSIS}

In this cross-sectional study, the prevalence rates were calculated in percent of total cases in each group and wherever applicable, prevalence amongst two groups was subjected to statistical analysis using Fisher's exact test and Chi-square test. The $p$ value of less than 0.05 was considered significant.

\section{REVIEW OF LITERATURE}

Diabetes mellitus is a disease characterized by persistent hyperglycemia, having acute and chronic biochemical and anatomical sequelae of multiple systems. ${ }^{1}$ Type 2 diabetes mellitus is the most common form, accounting for $85-95 \%$ of all cases worldwide. The World Health Organization has projected that the global prevalence will increase from 125 million in 1995 to 300 million by the year $2025 .^{2}$ According to the Diabetes Atlas 2006 published by the Indian Diabetes Federation, the number of people with diabetes is expected to be 69.9 million by 2025 . Majority of the patients with type 2 diabetes in developing countries are in the 45-64 year age group in contrast to developed countries where the majority of the diabetics are more than 64 years of age. ${ }^{3}$ It is more prevalent in the urban population and the main cause for the increase in the incidence is the change in dietary patterns and decreased physical activity. ${ }^{4}$

The metabolic disturbances of diabetes mellitus cause chronic irreversible damage to vital organs and systems. Though the cardiovascular, renal and ocular complications of diabetes are the most severe, there are various rheumatological manifestations which occur more frequently in patients with diabetes mellitus than in the general population. In contrast to various vascular complications of diabetes mellitus, which are life threatening, rheumatological manifestations lead to considerable morbidity. ${ }^{5}$

The rheumatological manifestations associated with diabetes mellitus can be classified under four categories.6:

\begin{tabular}{|c|c|}
\hline $\begin{array}{l}\text { Consequence } \\
\text { of diabetic } \\
\text { complications }\end{array}$ & $\begin{array}{l}\text { - } \quad \text { Diabetic muscular infarction } \\
\text { - } \quad \text { Neuropathic arthropathy }\end{array}$ \\
\hline $\begin{array}{l}\text { Consequences } \\
\text { of metabolic } \\
\text { derangements } \\
\text { inherent to } \\
\text { diabetes }\end{array}$ & $\begin{array}{l}\text { - Diffuse idiopathic skeletal } \\
\text { hyperostosis } \\
\text { - Osteopenia }\end{array}$ \\
\hline $\begin{array}{l}\text { With } \\
\text { mechanisms } \\
\text { with } \\
\text { microvascular } \\
\text { disease }\end{array}$ & $\begin{array}{l}\text { - Adhesive capsulitis of shoulder } \\
\text { - Dupuytren's disease } \\
\text { - Limited joint mobility syndrome } \\
\text { (Cheiroarthropathy) } \\
\text { - Palmar flexor tenosynovitis }\end{array}$ \\
\hline $\begin{array}{l}\text { Probable } \\
\text { association } \\
\text { with diabetes }\end{array}$ & $\begin{array}{ll}\text { - } & \text { Carpal tunnel syndrome } \\
\text { - } & \text { Gout } \\
\text { - } & \text { Osteoarthritis } \\
\end{array}$ \\
\hline
\end{tabular}

Diabetes mellitus affects connective tissues in many ways and cause different alterations in periarticular and skeletal system. ${ }^{7}$ Changes in the connective tissue of patients with diabetes are probably due to disturbances in the structural macromolecules of the extra cellular matrix. ${ }^{8}$

A study done by Cagliero E. ${ }^{9}$ showed prevalence of rheumatological manifestations was greater in diabetic patients $(36 \%)$ than in patients in the control group (9\%) and more common in patients with type 1 diabetes than in those with type 2 diabetes mellitus. A study done showed that $>30 \%$ of patients with diabetes have some hand or shoulder disease. ${ }^{10}$ Study done by Sarkar. ${ }^{5}$ showed that of the various rheumatological manifestations adhesive capsulitis, shoulder hand syndrome, diabetic hand syndrome diffuse idiopathic skeletal hyperostosis, Dupuytren's disease and neuroarthropathy are characteristically associated with diabetes mellitus. Other rheumatological conditions such as osteoarthritis of the knee, hip and spine, pseudo gout, osteolysis of forefoot are common in general population, but have an increased prevalence in the diabetic population. Most of the musculoskeletal manifestations seem to be associated with the duration of diabetes mellitus and appear in diabetic patients of younger age than their counter parts in general population.7,11

\section{Adhesive Capsulitis of Shoulder}

Adhesive capsulitis of shoulder is a common problem manifested by diffuse shoulder pain associated with loss of motion in all directions and little or no evidence of intraarticular disease. ${ }^{8}$ Bridgman. ${ }^{12}$ identified adhesive capsulitis in $11 \%$ of 800 diabetic patients as compared with $2.5 \%$ in 600 control patients. In $4.5 \%$ of the patients with adhesive capsulitis, both shoulders were involved. In the study done by Mavrikakis. ${ }^{13}$ it was found that $31.8 \%$ of diabetics had shoulder calcification compared with $10.3 \%$ of the control group. The calcific shoulder periarthritis was located in the right shoulder in $44.7 \%$, in the left shoulder in $26.7 \%$ and bilaterally in $28.6 \%$ of the patients with diabetes. Study done by Pal. ${ }^{14}$

Showed shoulder capsulitis was present in 19\% of patients with diabetes mellitus and $5 \%$ of normal subjects. In a study by Mavrikakis. ${ }^{13}$ of 824 type 2 diabetics \& 320 control subjects shoulder capsulitis was observed in $31.8 \%$ and $10.3 \%$ of subjects respectively. In the study done by Arkkila. ${ }^{15}$ also showed significant association between shoulder capsulitis in patients with type 2 diabetes mellitus. Diabetic shoulder capsulitis appears at a younger age, is less painful, respond less well to treatment and usually lasts longer than non-diabetic shoulder capsulitis.16 High frequency of other hand syndromes, such as limited joint mobility or cheiroarthropathy has been found among diabetic patients with shoulder capsulitis. ${ }^{17}$ Study done by Balci N. ${ }^{18}$ showed significant association of shoulder adhesive capsulitis with carpal tunnel syndrome, Dupuytren's disease and limited joint mobility syndrome.

\section{Shoulder Hand Syndrome}

The association of adhesive capsulitis with pain, swelling, dystrophic skin and vasomotor instability of the hand constitutes the "shoulder hand syndrome." It is a rare but potentially disabling manifestation of diabetes. ${ }^{19}$ Doury et al. described these syndromes as consisting of severe pain disproportionate to the findings of the physical examination in association with articular and periarticular swelling. ${ }^{8}$ Steinbrocker and Argyros described three stages of this syndrome. First stage lasts for 3-6 months and is characterised by pain, tenderness, swelling and vasomotor changes. The second stage lasts for 3-6 months and is characterised by trophic skin changes and in the final stage there is atrophy of skin and subcutaneous tissue, tendon contractures and progressive osteopenia. Motor abnormalities such as tremors, involuntary movements and muscle spasms have been reported. ${ }^{20}$

\section{Diabetic Cheiroarthropathy}

Diabetic cheiroarthropathy is also known as diabetic stiff hand syndrome, diabetic hand syndrome and syndrome of limited joint mobility. It is characterised by thick, tight, waxy skin with limited joint range of motion and sclerosis of tendon sheaths. ${ }^{21}$ The possible sites in the tissues leading to impaired mobility include alterations of the structures in the hand such as intrinsic muscle, joint capsule, subcutaneous tissues and alterations of structures extensive to the hand such as long flexor muscles and flexor tendons of forearm. ${ }^{22}$ 
A study done showed that limited joint mobility was significantly more frequent in the diabetic patients 36 out of 80 , than in the controls 7 out of 47 . Among patients who had diabetes for $>4.5$ years, 82 of 169 had joint limitation and $>50 \%$ of these patients had microvascular complications. ${ }^{23} \mathrm{~A}$ study by Michel. ${ }^{24}$ showed limited joint mobility was noted in 1/3rd of diabetics. It co-existed with Dupuytren's disease in $57 \%$ of insulin-dependent diabetics. Limited joint mobility is more prevalent in patients with diabetic neuropathy than in those without. ${ }^{25}$ Study by Renard E. ${ }^{26}$ showed prevalence of various soft tissue hand lesions was higher in both type 1 and type 2 diabetics (33.3 and $26.7 \%$ ) than in their control population (5.0 and $8.3 \%$ ).

\section{Dupuytren's Disease}

Thickening, shortening, fibrosis and nodule formation of the palmar fascia, resulting in the flexion contracture of the fingers is termed Dupuytren's contracture. In patients with diabetes, ring and middle finger are more commonly affected compared to the fifth finger in patients without diabetes. ${ }^{27}$ The pathogenesis of Dupuytren's contracture due to proliferation of modified fibroblasts that resemble smooth muscle cells with subsequent contraction, might subject neighbouring fascial structures to intermittent tension resulting in hypertrophy. Other studies have documented the deposition of increased amounts of type 2 collagen in the palmar aponeurosis. ${ }^{8}$ Dupuytren's contracture occurs in more than $1 / 3$ rd of the patients with diabetes, especially those with longstanding poorly controlled diabetes. ${ }^{28}$ Prevalence of Dupuytren's contracture in diabetic patients ranges from 20-63\% compared to $13 \%$ in the general population. ${ }^{29}$

\section{Carpal Tunnel Syndrome}

Carpal tunnel syndrome is characterized by paraesthesia over the median nerve cutaneous distribution, due to compression of median nerve within carpal tunnel. ${ }^{29}$ Its specific relation to diabetes is thought to be due to median nerve entrapment caused by diabetes induced connective tissue changes. Tinel's sign and Phalen's test assist in the diagnosis of CTS. CTS is more common in women than men. The prevalence of CTS in diabetic patients increases with the duration of diabetes. ${ }^{21}$

\section{Neuroarthropathy}

Neuroarthropathy is a severe destructive form of degenerative arthritis resulting from loss of sensation in the involved joints, called as Charcot's joints or diabetic osteoarthropathy. ${ }^{21}$ Diabetes is one of the major causes of Charcot's joints. The foot is most commonly involved followed by ankle and knee. Unilateral painless foot swelling is the most common finding. Radiographically, there are destructive changes of the tars metatarsal and metatarsophalyngeal joints, which include circumscribed osteoporosis, subluxation, osteolysis, fractures and periosteal reactions. ${ }^{30,31}$

\section{Diffuse Idiopathic Skeletal Hyperostosis}

Diffuse idiopathic skeletal hyperostosis is also known as ankylosing hyperostosis, characterized by flowing calcification of paraspinal ligaments, commonly affecting thoracic spine followed by the lumbar and cervical spine. ${ }^{1} \mathrm{~A}$ proposed pathogenesis for the occurrence of DISH in patients with diabetes mellitus is the prolonged and high levels of insulin and insulin like growth factors occurring in diabetic patients, which stimulates new bone formation.30,31 Pain, stiffness, dysphagia and other neurological abnormalities are the main clinical features of DISH. ${ }^{32}$ It is more common in males and seen in persons, above the age of 50 years. Study done by Daragon. 33 has shown association of DISH and diabetes mellitus. In the study done by Sencan D. ${ }^{34}$ prevalence of DISH was $12 \%$ in diabetics as compared to $6.8 \%$ in the control group.

A study by Belanger. ${ }^{35}$ has shown that the DISH is seen in $13-49 \%$ of diabetic patients and $1.6-13 \%$ of non-diabetic patients. Approximately, $70 \%$ of patients with DISH have manifestations involving foot and ankle. ${ }^{36}$ Study done by Vezyroglou. ${ }^{37}$ showed higher prevalence of dyslipidemia, diabetes and hyperuricemia in patients with DISH. In the study by Harris et al. ${ }^{38}$ diabetes was found in high proportion of cases with DISH. In the study by Julkunen et al. ${ }^{39} 13 \%$ of 510 diabetics had ankylosing spondylosis on X-ray.

\section{Osteoarthritis}

Osteoarthritis or degenerative joint disease, commonly involves the large weightbearing joints. The prevalence of osteoarthritis of large and small joints is higher among patients with diabetes. ${ }^{6}$ The incidence is more in type 2 diabetics. $^{21}$ Crispond Heathcoate reported that OA is more common in young and middle aged diabetics. The joint damage starts at a much earlier age and is more severe in diabetics than in control population. Study done by Sarkar. ${ }^{5}$ showed osteoarthritis and diabetes have a positive correlation. It was observed in $31.1 \%$ of diabetic patients.

\section{Gout}

Gout is a disorder characterised by hyperuricemia and arthritis, affects lower extremities. ${ }^{8}$ In the study conducted by Sarkar. ${ }^{5}$ acute gouty arthritis was seen in only $0.8 \%$ cases, although symptomatic hyperuricemia was seen in $3 \%$ patients with diabetes mellitus.

\section{Osteopenia}

There is controversy regarding occurrence of osteopenia and osteoporosis in patients with diabetes mellitus. A $14 \%$ reduction in trabecular bone density and $8 \%$ reduction in the cortical bone density has been seen in children with diabetes and a similar reduction is noted in the adults. ${ }^{8}$ Study done by Yi-Jen Heung. ${ }^{40}$ showed significantly lower bone mineral density in patients with diabetes than in the control group. McNair et al. has reported that bone mineral density was nearly normal at the onset of clinical diabetes and bone mineral content decreased about $10 \%$ within 5 year of diabetes. The mechanism responsible for osteopenia may be increased blood flow, secondary sympathetic denervation or poor diabetic control. ${ }^{31}$

\section{Osteolysis of Forefoot}

Osteolysis of forefoot is a distinct clinical syndrome that is characterised by patchy or generalised osteoporosis of distal metatarsal and proximal phalanges with variable pain and erythema that has been described in patients with diabetes. ${ }^{8}$ Articular surfaces are initially spared but progressive osteolysis can lead to disappearance of the adjacent bone. It should be differentiated from cellulitis and osteomyelitis. ${ }^{31}$

\section{Flexor Tenosynovitis}

Flexor tenosynovitis or trigger finger is caused by fibrous tissue proliferation in the tendon sheath leading to limitation of the normal movement of the tendon. ${ }^{29}$

\section{RESULTS}

- $32 \%$ (32 patients) among diabetics belonged to the age group of 61 to 70 years and in non-diabetics 32\% (16 patients) belonged to age group of 41 to 50 years. Mean age of the diabetics was $57.59 \pm 10.44$ years and nondiabetics was $52.40 \pm 10.36$ years.

- In the 100 diabetics included in the study, $61 \%$ were males and $39 \%$ were females. Out of 50 non-diabetics, $50 \%$ were males and $50 \%$ were females. 
- Majority of the diabetic population (37\%) had 1-5 years of duration of the disease. Mean duration of disease was $7 \pm 6.99$ years.

- Rheumatological manifestations were seen in 31 patients (31\%) with type 2 diabetes mellitus and 8 patients $(16 \%)$ without diabetes. It is statistically significant with $\mathrm{p}$ value of 0.048 calculated using Pearson's Chi square test.

- Among the 31 type 2 diabetics with rheumatological manifestations, the commonest is periarthritis of shoulder accounting for $55 \%$ of the cases.

- Among the 31 diabetic patients with manifestations, 16 had frozen shoulder, 6 had osteoarthritis of the knee, 3 had DISH, 3 had carpal tunnel syndrome and 1 had Charcot joint of the ankle. Both osteoarthritis of knee and periarthritis of shoulder were seen in 2 diabetics. Among 8 non-diabetic patients with rheumatological manifestations, 2 had frozen shoulder, 5 had osteoarthritis of the knee, and 1 had carpal tunnel syndrome. None of them were found to have cheiroarthropathy, flexor tenosynovitis and Dupuytren's contracture. A statistically significant association was found for the prevalence of periarthritis among type 2 diabetics and non-diabetics ( $\mathrm{p}$ value $=0.033$ ).

- The prevalence of rheumatological manifestations in the diabetic population is greater in females $(43.6 \%)$ as compared to males (23\%), which is statistically significant $(p=0.03)$. In case of non-diabetics it is more common in females, but is statistically insignificant $(p=$ 0.123 ).

- The rheumatological manifestations were more prevalent in 51-60 year age group followed by 61 to 70 year age group among diabetics. In the non-diabetics, it was commonly found in age group of 51 to 60 years.

- The mean value of RA factor was $11.51 \mathrm{IU} / \mathrm{ml}$ in diabetics with manifestations as compared to $22.41 \mathrm{IU} / \mathrm{ml}$ in case of non-diabetics. No significant difference is noted in RA factor in diabetics with and without rheumatological manifestations.

\section{DISCUSSION}

In the present study, prevalence of rheumatological manifestations was greater in patients with type 2 diabetes mellitus (31\%) compared to the non-diabetics (16\%). It is consistent with the study done by Caglerio E. ${ }^{9}$ in which $36 \%$ of the diabetics had rheumatological manifestations as compared to $9 \%$ of non-diabetics and study done by Douloumpakas. ${ }^{7}$ which showed $82.6 \%$ of type 2 diabetics had rheumatological manifestations.

Periarthritis of the shoulder was found in $18 \%$ of the type 2 diabetics as compared to $6 \%$ non-diabetics in the present study. Among the 18 diabetic patients with periarthritis of shoulder, it was found unilaterally in $83.4 \%$ and bilaterally in $16.6 \%$ of the patients. The bilateral involvement was more frequent in diabetics $(16.6 \%)$ than in non-diabetics (0\%). In our study $8 \%$ of the diabetics and $10 \%$ of the non-diabetics had osteoarthritis and mainly knee joint was involved. It is inconsistent with the study done by Sarkar RN. 5 in which osteoarthritis was found in $31 \%$ of the diabetics out of which $85 \%$ were type 2 diabetics and usually found to involve the non-weightbearing joints. Increased prevalence was seen in females than males which was consistent with the study done by Sarkar RN. ${ }^{5}$ Diffuse idiopathic skeletal hyperostosis is seen only in $3 \%$ of the type 2 diabetics as compared to $2 \%$ of the non-diabetics, which was not consistent with the various studies. ${ }^{33,35-38}$ which reported increased prevalence of diffuse idiopathic skeletal hyperostosis in diabetics as compared to non-diabetics.
From various studies we can conclude that adhesive capsulitis, diabetic hand syndrome, Dupuytren's contracture and DISH are more prevalent in diabetics than non-diabetics.

\section{SUMMARY AND CONCLUSION}

- A statistically significant correlation in the prevalence of rheumatological manifestations among patients with type 2 diabetes mellitus than non-diabetics, hence they should be monitored regularly. The rheumatological manifestations were more prevalent in females as compared to males in the diabetic population. In type 2 diabetics periarthritis of shoulder was the common manifestation, found unilaterally in $83.4 \%$ and bilaterally in $16.6 \%$ of patients.

\section{BIBLIOGRAPHY}

1. Wyatt LH, Ferrance RJ. The musculoskeletal effects of diabetes mellitus. J Can Chiropr Assoc.

2006;50(1):43-50.

2. Wild S, Roglic G, Green A, et al. Global prevalence of diabetes. Estimates for the year 2000 and projections for the year 2030. Diabetes Care. 2004;27:1047-53.

3. Mohan V, Sandeep S, Deepa R, et al. Epidemiology of type 2 diabetes: Indian scenario. Indian J Med Res 2007;125:217-30.

4. Koopman RJ, Mainous AG, Diaz VA, et al. Changes at the age at diagnosis of type 2 diabetes mellitus in the United States, 1988 to 2000. Ann Fam Med. 2005;5:60-3.

5. Sarkar RN, Banerjee S, Basu AK, et al. Rheumatological manifestations of diabetes mellitus. J Ind Rheumatol Assoc. 2003;11:25-9.

6. Crispin JC, Varela JA. Rheumatologic manifestations of diabetes mellitus. Am J Med. 2003;114(9):753-7.

7. Douloumpakas I, Pyrpasopoulou A, Triantafyllou A, et al. Prevalence of musculoskeletal disorders in patients with type 2 diabetes mellitus: a pilot study. Hippokratia. 2007;114:216-8.

8. Husni ME, Kroop SF, Simon LS. Joint and bone manifestations of diabetes mellitus. In: Kahn CR, Weir GC, eds Joslin's Diabetes Mellitus. Pennsylvania. Lea and Febiger; 2000;14 ed: 1061-6.

9. Cagliero E, Apruzzese W, Perlmutter GS, et al. Musculoskeletal disorders of the hand and shoulder in patients with diabetes mellitus. Am J Med. 2002;112(6):489-92.

10. Cagliero E. Rheumatic manifestations of diabetes mellitus. Current Rheumatology Reports. 2003;5(3):189-94.

11. Nathan DM. Long-term complications of diabetes mellitus. N Engl J Med. 1993;328:1676-85.

12. Bridgman JF. Periarthritis of the shoulder and diabetes mellitus. Ann Rheum Dis. 1972;31:69-71.

13. Mavrikakis ME, Drimis S, Kontoyannis DA, Rasidakis A, Moulopoulou ES, Kontoyannis S. Calcific shoulder periarthritis (tendinitis) in adult onset diabetes mellitus: a controlled study. Ann Rheum Dis. 1989;48:211-14.

14. Pal B, Anderson J, Dick WC, et al. Limitation of joint mobility and shoulder capsulitis in insulin and noninsulin dependent diabetes mellitus. $\mathrm{Br} \mathrm{J}$ Rheum 1986;25(2):147-51.

15. Arkkila PET, Kantola IM, Viikari JSA, et al. Shoulder capsulitis in type I and II diabetic patients: association with diabetic complications and related diseases. Ann Rheum Dis. 1996;55:907-14.

16. Crisp AJ. Diabetes mellitus and the rheumatologist. Br J Rheumatol. 1986;25:135-40. 
17. Fisher L, Kurtz A, Shipley M. Association between cheiroarthropathy and frozen shoulder in patients with insulin-dependent diabetes mellitus. Br J Rheumatol. 1986;25:141-6.

18. Balci N, Balci MK, Tuzuner S. Shoulder adhesive capsulitis and shoulder range of motion in type II diabetes mellitus: association with diabetic complications. J Diabetes Complications. 1999;13:135-40.

19. Rosenbloom AL, Silverstein JH. Connective tissue and joint disease in diabetes mellitus. Endocrinol Metab Clin North Am. 1996;25:473-83.

20. Marshall AT, Crisp AJ. Reflex sympathetic dystrophy. Br J Rheumatol 2000;39:692-5.

21. Kim RP, Edelman SV, Kim DD. Musculoskeletal complications of diabetes mellitus. Clinical Diabetes. 2001;19(3):132-5.

22. Fitzcharles MA, Duby S, Waddell RW, et al. Limitation of joint mobility (cheiroarthropathy) in adult noninsulindependent diabetic patients. Ann Rheum Dis. 1984;43:251-7.

23. Rosenbloom AL, Silverstein JH, Lezotte DC, et al. Limited joint mobility in childhood diabetes mellitus indicates increased risk for microvascular disease. N Engl J Med. 1981;305:191-4.

24. Chammas M, Bousquet P, Renard E, Poirier JL, Jaffiol C, Allieu Y. Dupuytren's disease, carpal tunnel syndrome, trigger finger and diabetes mellitus. The J Hand Surg. 1995;20(1):109-14.

25. Jennings AM, Milner PC, Ward JD. Hand abnormalities are associated with the complications of diabetes in type 2 diabetes. Diabet Med. 1989;6:43-7.

26. Renard E, Jacques D, Chammas M, Poirier JL, Bonifacj C, Jaffiol C, et al. Increased prevalence of soft tissue hand lesions in type 1 and type 2 diabetes mellitus: various entities and associated significance. Diabet Metab. 1994;20(6):513-21.

27. Noble J, Heathcote JG, Cohen H. Diabetes mellitus in the aetiology of Dupuytren's disease. J Bone Joint Surg [Br] 1984;66:322-5.
28. Gamstedt A, Glad JH, Ohlson CG, et al. Hand abnormalities are strongly associated with the duration of diabetes mellitus. J Intern Med. 1993;234:189-93.

29. Smith LL, Burnet SP, McNeil JD. Musculoskeletal manifestations of diabetes mellitus. Br J Sports Med 2003;37:30-5.

30. Holt PJL. Rheumatological manifestations of diabetes mellitus. Clin Rheum Dis 1981;7:723-46.

31. Dashora UK. Musculoskeletal Features of Diabetes Mellitus. Int J Diab Dev Countries. 1994;14:129-33.

32. Kiss C, Szilagyi M, Paksy A, et al. Risk factors for diffuse idiopathic skeletal hyperostosis: a case-control study. Rheumatology. 2002;41:27-30.

33. Daragon A, Mejjad O, Czernichow P. Vertebral hyperostosis and diabetes mellitus: A case-control study. Ann Rheum Dis. 1995;54:375-8.

34. Sencan D, Elden H, Nacitarhan V, et al. The prevalence of diffuse idiopathic skeletal hyperostosis in patients with diabetes mellitus. Rheumatol Int. 2005;25:518-21.

35. Belanger TA, Rowe DE. Diffuse Idiopathic Skeletal Hyperostosis: Musculoskeletal Manifestations. J Am Acad Orthop Surg. 2001;9:258-67.

36. Forgacs SS. Diabetes mellitus and rheumatic disease. Clin Rheum Dis. 1986;12:729-53.

37. Vezyroglou G, Mitropoulos A, Kyriazis N, et al. A metabolic syndrome in diffuse idiopathic skeletal hyperostosis. A controlled study. J Rheumatol. 1996;23:672-6.

38. Harris J, Carter AR, Glick EN. Ankylosing hyperostosis. Clinical and radiological features. Ann Rheum Dis. 1974;33:210.

39. Julkunen H, Heinone OP, Pyorala K. Hyperostosis of the spine in an adult population. Ann Rheum Dis. 1971;30:605.

40. Hueng YJ, Kuo SW, Wu DA, et al. Study of bone mineral loss in insulin dependent diabetes mellitus. J Med Sci. 1997;18(2):85-91.

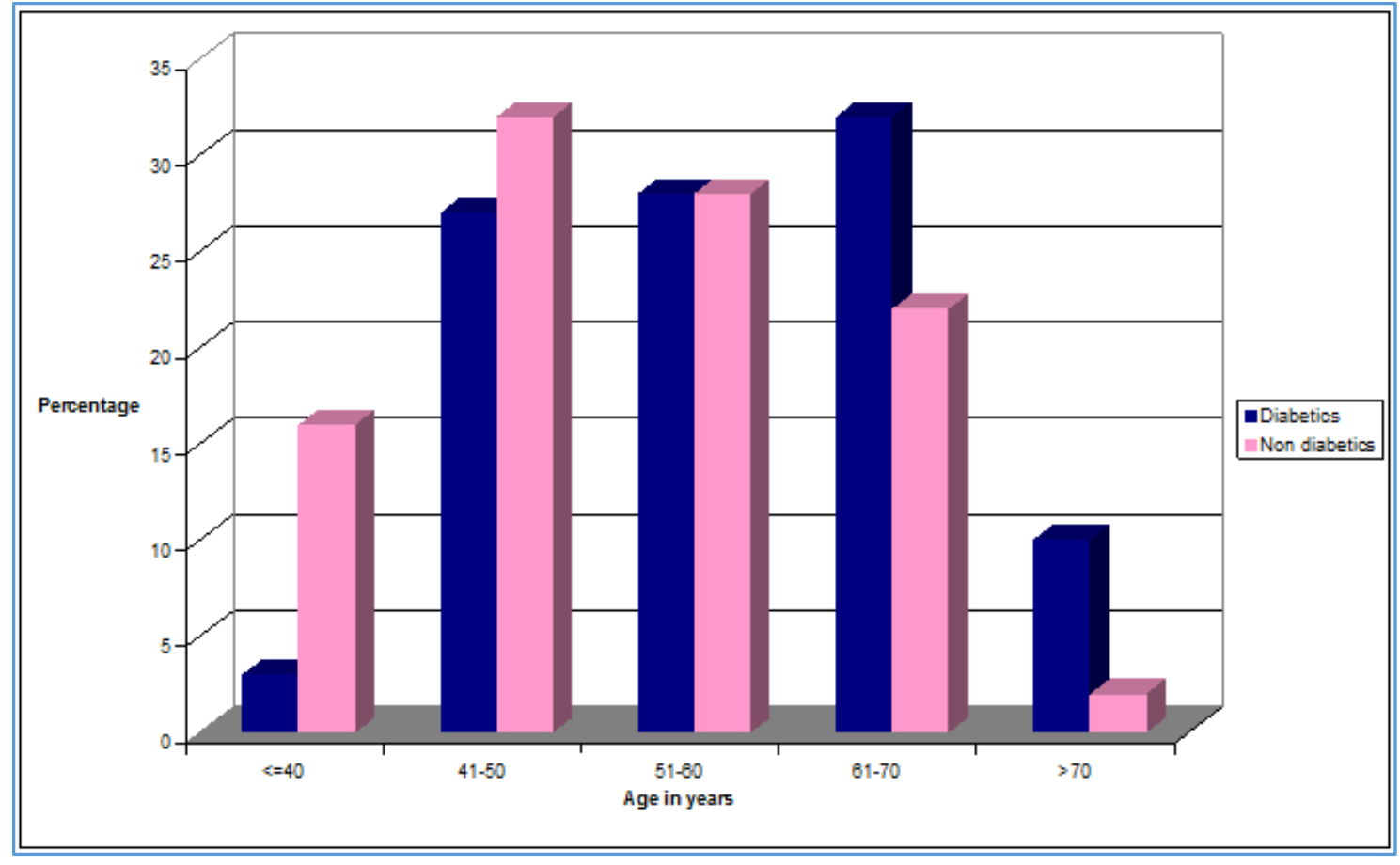

Fig. 1: Age Distribution 


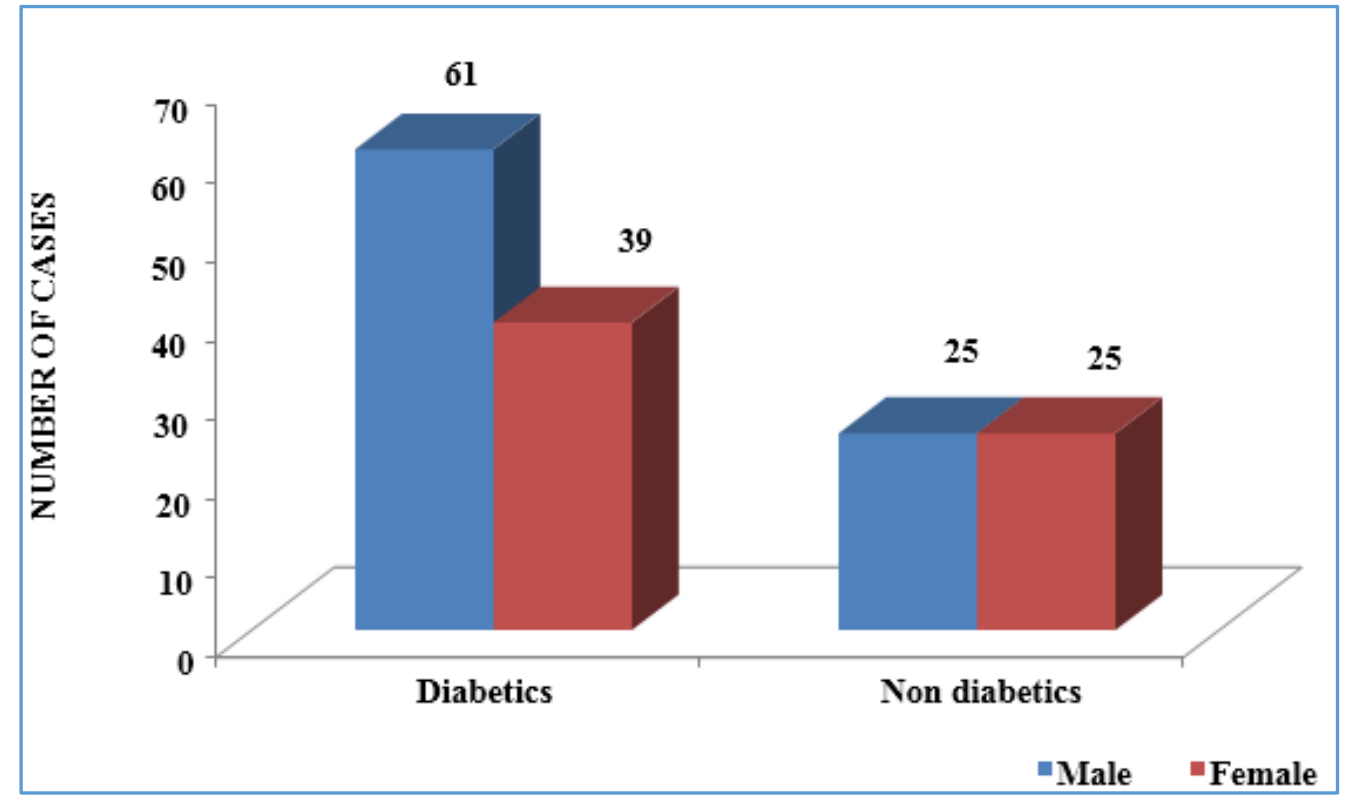

Fig. 2: Sex Distribution

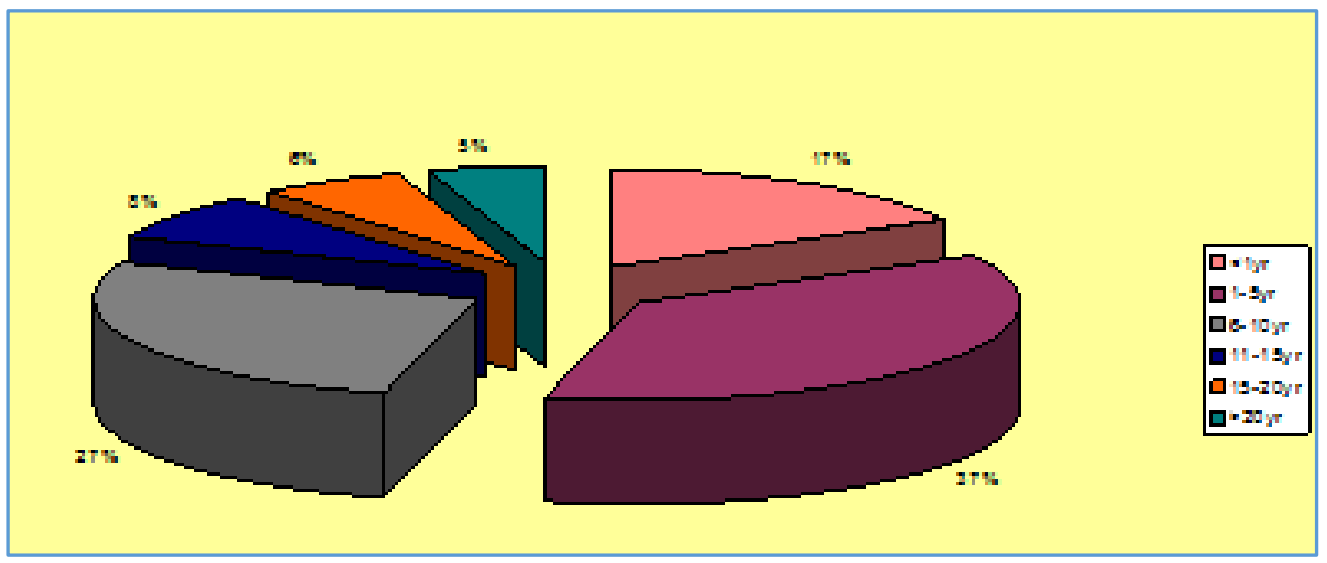

Fig. 3: Duration of Diabetes

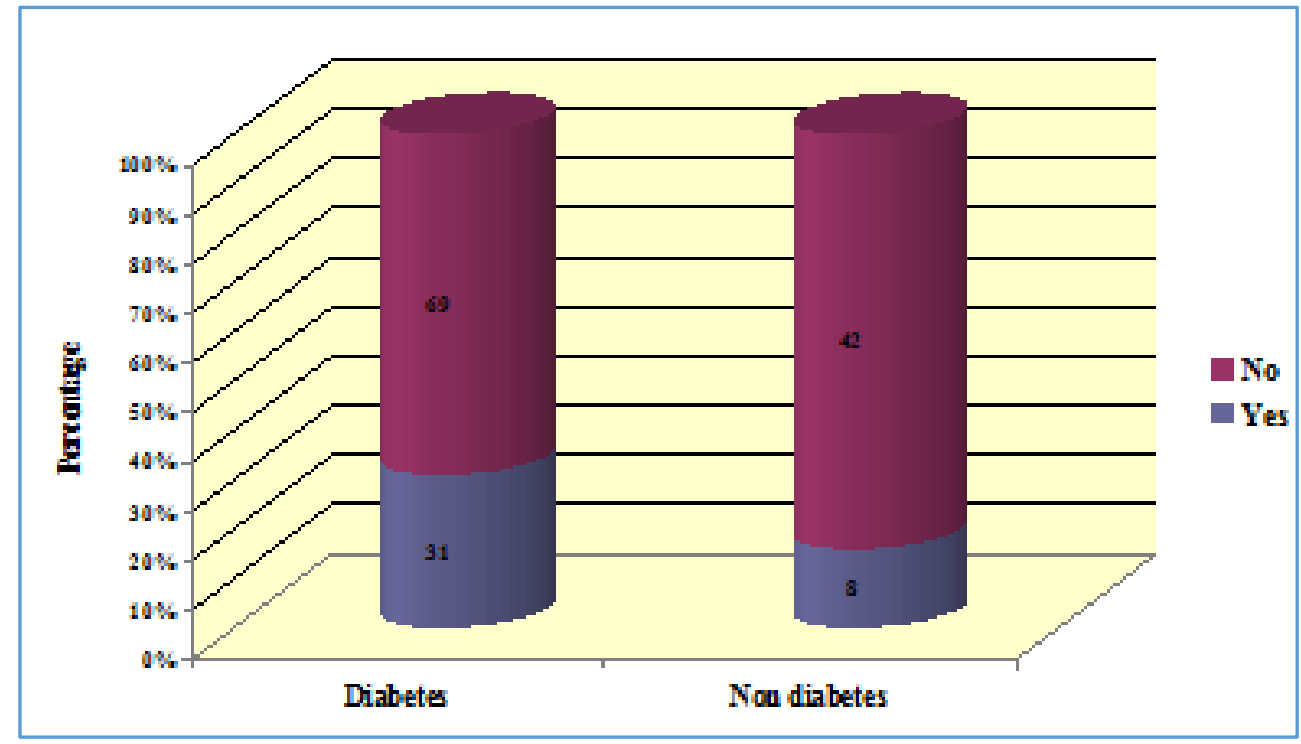

Fig. 4: Prevalence of Rheumatological Manifestations

Yes $=$ Patients with rheumatological manifestations.

No $=$ Patients without rheumatological manifestations. 


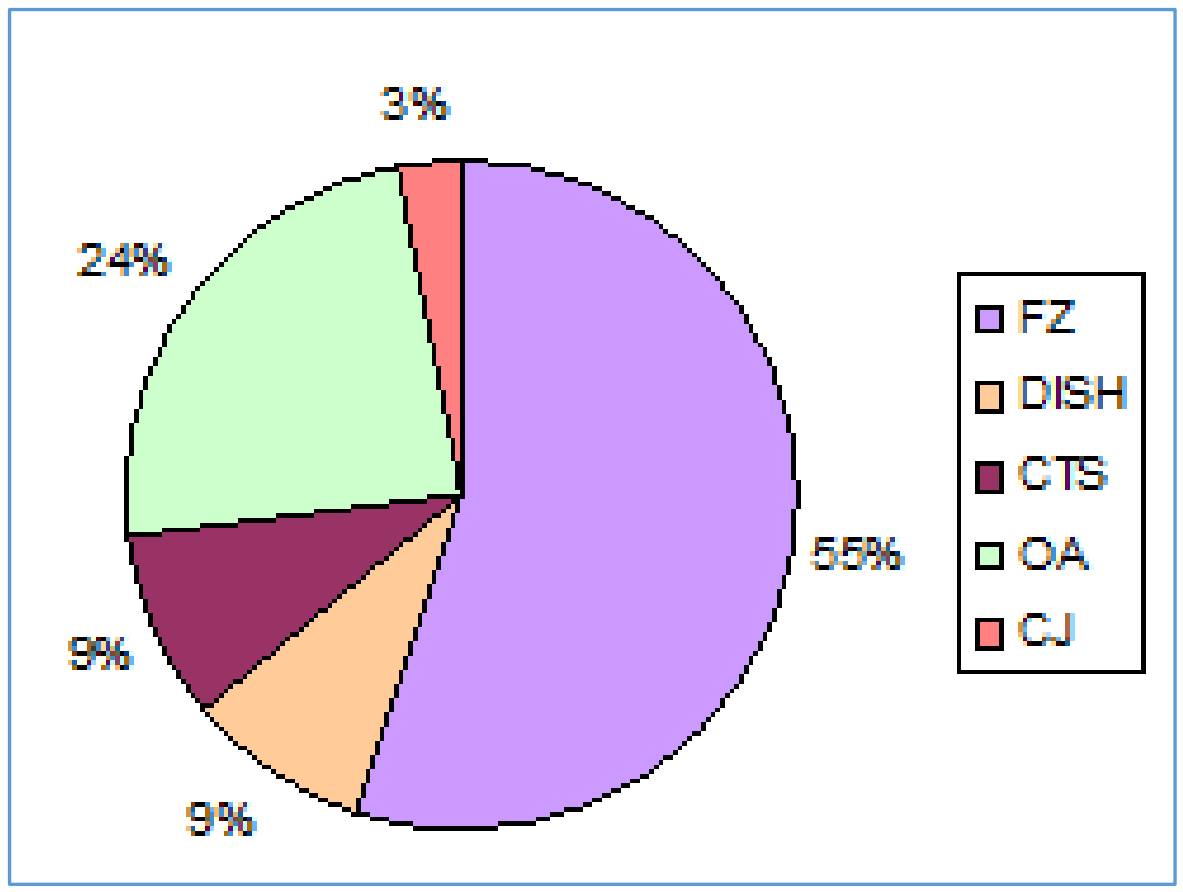

Fig.5: Rheumatological manifestations in patients with Type 2 Diabetes Mellitus

FZ - Frozen shoulder

DISH-Diffuse Idiopathic Skeletal Hyperostosis

CTS-Carpal Tunnel Syndrome

OA-Osteoarthritis

CJ-Charcot's Joint

Among the 31 type 2 diabetics with rheumatological manifestations, the commonest is periarthritis of shoulder accounting for $55 \%$ of the cases.

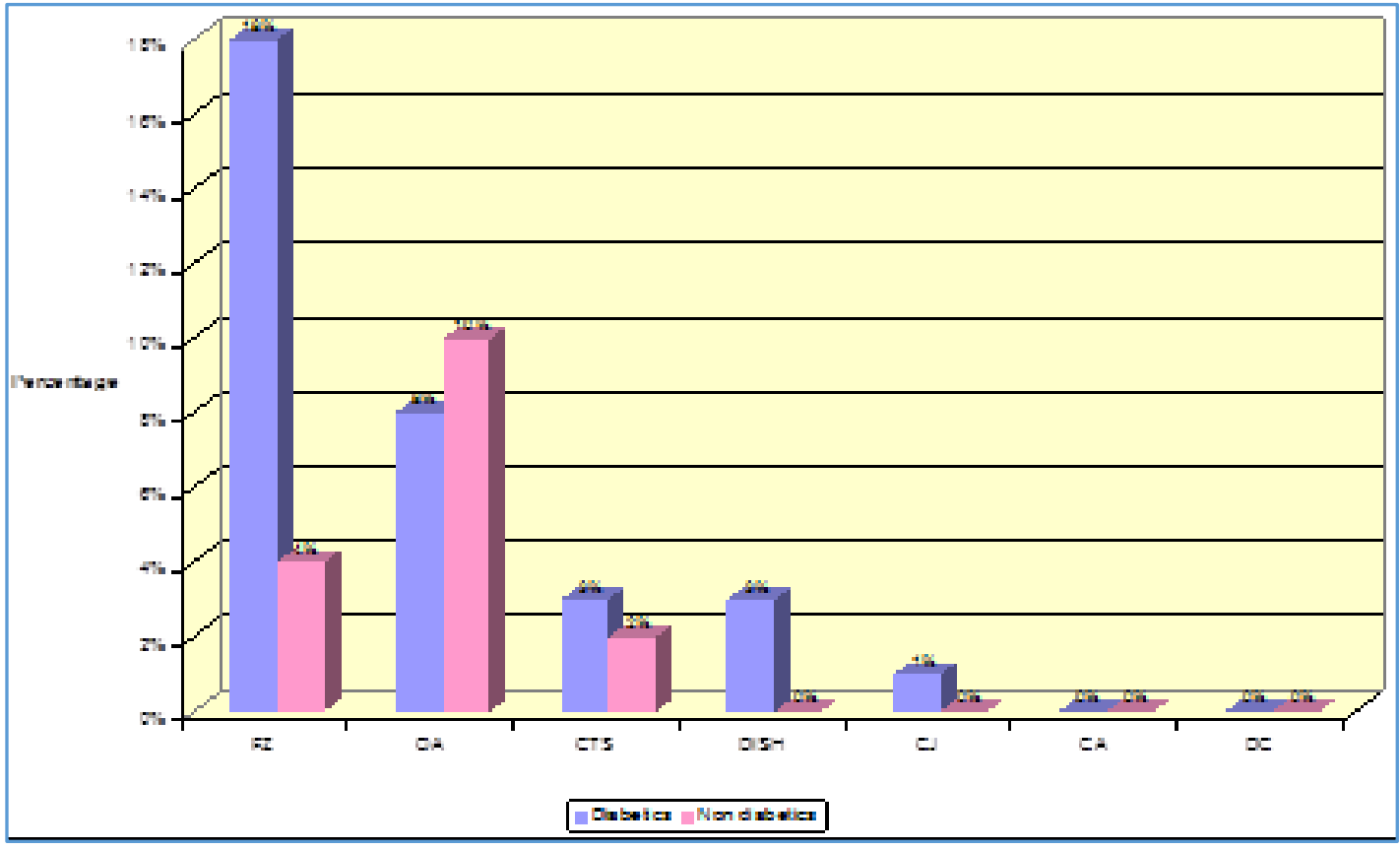

Fig.6: Comparison of prevalence of various Rheumatological manifestations among Diabetics and Non-Diabetics

FZ -Frozen shoulder

CTS-Carpal Tunnel Syndrome

CJ-Charcot's Joint

DC-Dupuytren's Contracture
DISH-Diffuse Idiopathic Skeletal Hyperostosis

OA-Osteoarthritis

CA-Cheiroarthropathy 


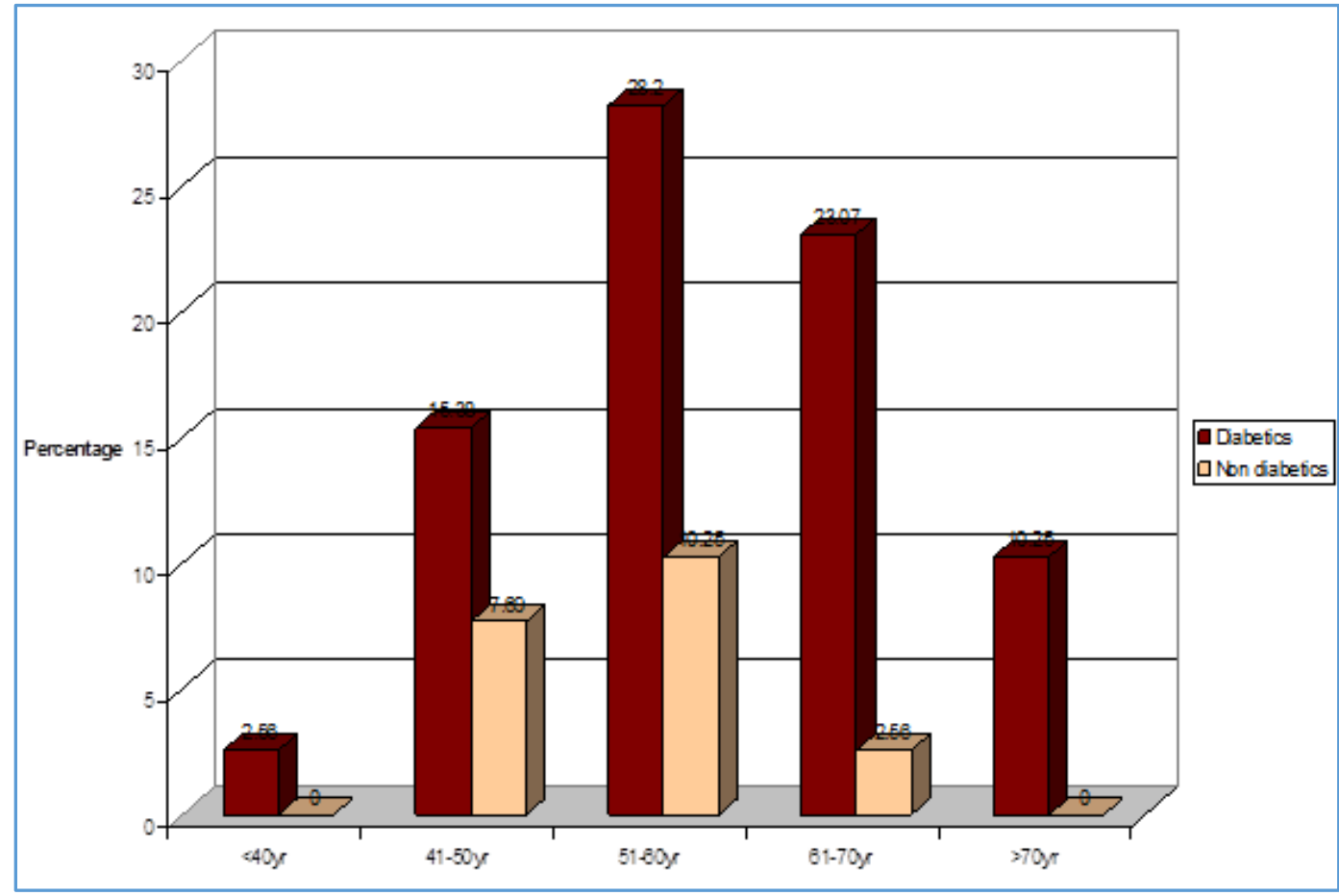

Fig.7: Age wise distribution of Rheumatological manifestations among Diabetics and Non-Diabetics

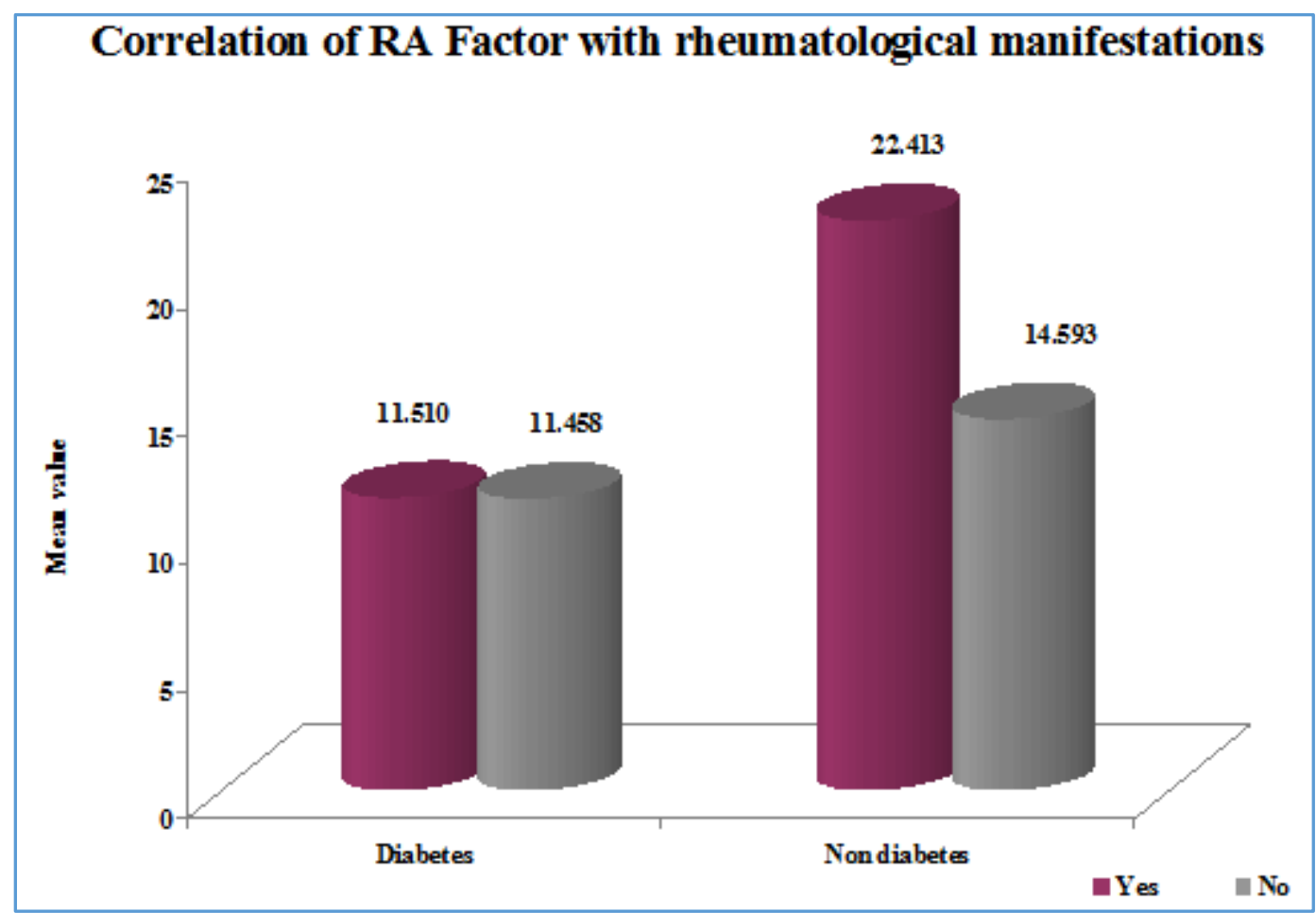

Fig.8: Correlation of Rheumatological manifestations with Rheumatoid Factor

Yes $=$ Patients with rheumatological manifestations

No = Patients without rheumatological manifestations

\begin{tabular}{|c|c|c|c|}
\hline Group & Manifestations & Males & Females \\
\hline \multirow{3}{*}{ Diabetics } & Present & $14(23 \%)$ & $17(43.6 \%)$ \\
\hline & Absent & 47 (77\%) & $22(56.4 \%)$ \\
\hline & Total & $61(100 \%)$ & $39(100 \%)$ \\
\hline \multirow{3}{*}{ Non-diabetics } & Present & $2(8 \%)$ & $6(24 \%)$ \\
\hline & Absent & $23(92 \%)$ & $19(76 \%)$ \\
\hline & Total & $25(100 \%)$ & $25(100 \%)$ \\
\hline
\end{tabular}




\begin{tabular}{|c|c|c|}
\hline STUDY & DIABETICS & NONDIABETICS \\
\hline Sarkar RN. ${ }^{5}$ & $17.9 \%$ & $7 \%$ \\
\hline Bridgman. $^{12}$ & $11 \%$ & $2.5 \%$ \\
\hline Mavrikakis. $^{13}$ & $31.8 \%$ & $10.3 \%$ \\
\hline Pal. $^{14}$ & $19 \%$ & $5 \%$ \\
\hline Cagleiro E. $^{9}$ & $12 \%$ & $0 \%$ \\
\hline Table2: Comparison of the present study with other studies for the prevalence of Periarthritis $^{\text {in Type 2 Diabetics and Non-Diabetics }}$ \\
\hline
\end{tabular}

